\title{
Integrating Sustainability in Project Management: A Case Study of Anhui Ligong Real Estate Co. Ltd., Anhui
}

\author{
Linda Abangbila $^{*}\left(\mathbb{D}\right.$, Xiezhen An$^{1}$, Akwi Helene Fomude ${ }^{1}\left(\mathbb{C}\right.$, Nii Odartey Lamptey $^{2}$ \\ ${ }^{1}$ School of Economics and Management, Anhui University of Science and Technology, Huainan, China \\ ${ }^{2}$ Methodist University College, Accra, Ghana \\ Email: *sabangbila@gmail.com, zhaxie@aust.edu.cn, lenafomude@gmail.com,nii_odartey@yahoo.com
}

How to cite this paper: Abangbila, L., An, X. Z., Fomude, A. H., \& Lamptey, N. O. (2020). Integrating Sustainability in Project Management: A Case Study of Anhui Ligong Real Estate Co. Ltd., Anhui. Open Journal of Business and Management, 8 , 2113-2132.

https://doi.org/10.4236/ojbm.2020.85129

Received: July 18, 2020

Accepted: September 1, 2020

Published: September 4, 2020

Copyright $\odot 2020$ by author(s) and Scientific Research Publishing Inc. This work is licensed under the Creative Commons Attribution International License (CC BY 4.0).

http://creativecommons.org/licenses/by/4.0/ (c) (i) Open Access

\begin{abstract}
Sustainability has evolved into being a recognized component of decision making. Also, integrating sustainability in project management has had dynamism in the research field over the few last decades. The absorption and demand for sustainability in the development market are increasing, as the focus of concretizing the idea of sustainability within challenging projects. This research shows how sustainability can be incorporated into the project by a project manager and in the project management process by being more proactive in meeting customer needs and demands. However, we work hand in hand with Program managers to optimize green construction design and environmental protection. Third-party agencies also conduct environmental assessments to know how sustainable the project to meet the demands of the future generation. This paper presents a discussion on which project management roles have what influence sustainability in the process of project management by using the Turner's Model to investigate whether the assumptions made by Turner are true for the case "Anli Homeland" project. Data were drawn from five interviews administered with the major partners (program manager, project manager, two deputy project managers, and the client) of these five all are valid, analyzed, and juxtaposed to the model. The results show the project manager possesses medium responsibility regarding the holistic approach; he also has a towering responsibility for participation and low control for long term view and risk reduction. This perception is established on the notion that a project leader is internally stimulated to work on a project and attain a more sustainable outcome. Ideally, this research is to mitigate negligence along with raising the confidence amongst project leaders to consistently engage in sustainability work through new methods and routines.
\end{abstract}




\section{Keywords}

Sustainability, Project, Sustainability in Projects, Project Management, Turner's Model

\section{Introduction}

In 2015, the Sustainable Development Goals were profound by the United Nations General Assembly intended to be attained by the year 2030, which is part of UN Resolution 70/1, the 2030 Agenda. Under growing political interest, the merits of sustainability as an academic field of research and practice have risen. Currently, it is seen as increasingly academic research that takes into consideration how sustainability may be attained as a vital scheme. Particularly, research has emphasized governments (UNCTAD, 2014), corporations and, the broader community's role. Widely, a body of service concentrates on large level sustainability issues (e.g.: change in climate, use of natural resources).

Practicality and micro-level concerns are less prominent; especially the part of cognizance and professional workers as actual mediators in establishing a sustainable economy and society has gotten far less attention. This relates to what Nelmara Arbex said: "We need to adopt new ways of perceiving things to alter the way we do things". Once individuals have a changed and positive mentality, it would lead to growth. It can be taken into account that concepts of sustainability solely concern either harmonizing or balancing environmental, social and economic needs by taking note of both the short and the long term areas which are also called the "Triple P Bottom Line" (Elkington, 1999): People (social), Planet (environmental) and Profit (economical). Change driven towards sustainability requires an adaptation in all the three pillars of the triple bottom line. However, it can be debatable if it is of relevance at all times to grant each of the triple bottom lines, the same consideration or that would not be feasible. A project is a temporary activity that has a beginning and an end date, unique, brings change and, has unknown elements, which creates risk. Project Managers are substantially jugglers. They must ensure everything to aim at a task that potential issues are quickly gotten rid of and the project is delivered timely while making sure everyone is aware of any occurrence and the quality of the project and budget are acceptable. Specifically, they aim at all activities needed to meet the project objectives successfully, manage risk-scanning ahead for potential issues and settling them before they become a problem, solve problems, proposing alternative perspectives to issues that arise and providing guidance to the Project Sponsor, track and report project progress and communicate to all stakeholders in the project.

In the area of project, management sustainability and project management have been explored by different researchers. However, just a few of these studies 
are observed in discovering contemporary methods for the usage and assessment of sustainable project management. Seemingly, sustainability ensures financial, integrates social and, natural control elements to utilize present resources judicially, and also to give the same for coming future generations worldwide (Kleindorfer et al., 2005).

The aim of this research paper is on integrating sustainability in Project Management, as an instance of an important profession, in contributing to a sustainable economy, society and can influence the way sustainability is implemented in the project management process and the project. This is crucial because project managers as professionals are competent, possess technical knowledge, and the skills needed to implement sustainable initiatives successfully. This research paper identifies various factors of sustainability outlined by eminent researchers along with the sustainable policies and process of selection of numerous measures to incorporate sustainability into projects. Based on this, a possibility for a new horizon for research and analysis in the area of sustainable project management is said to be:

- Substantial computational procedures and rising algorithms can be used in the area of sustainable project management so that prime level of resources can be estimated and rightly used.

- Some critical parameters from sustainable project management include profitability, safety, transparency, ethicality, nature-friendly, social acceptability, achieving the stakeholders and the customer's expectations were studied to use above mentioned parameters as the weighting parameters in the multi-objective sustainable project management problems to point out and scale the sustainability issues for the projects under deliberation.

- A new coherent framework for gauging sustainability in project management by incorporation and appraisal of response function, for each and every venture, decision and policy by the organization are also granted and reviewed.

Similarly, engineers have engaged actively in developing sustainable "green" technologies, so too have project managers been involved in development and diffusion of sustainable practices, and as such, this research focuses on how the PM profession has added up to development and sustainability principles and practices.

This study is structured as follows: the introduction to the study is presented in Section 1. Section 2 contains literature on project management sustainability. The methodology employed in this study is presented in Section 3. Results \& discussions and conclusion are presented in Sections 4 and 5 respectively

\section{Literature Review on Project Management (PM) and Sustainability}

Increasingly projects are based on economic activity, which makes these, projects more sustainable serving as building blocks for a more sustainable economy and society. Accordingly, a growing debate amongst practitioners is 
concentrating on the issue of sustainable projects. As part of the drive towards sustainable projects, PM has created several new methodologies, tools, and techniques that foreground focus sustainability (e.g.: the GPM P5 Standard for Sustainability in Project Management; or Project Management Global Sustainability Community of Practice).

Theoretically, the prominence of project managers is not limited to their practical roles as facilitators of sustainable, technical solutions, such as the sustainable projects described above, but refers to the wider institutional role that professions exercise in achieving radical change. Delivering sustainability is important as this may require challenging supposition and practices which are greatly institutionalized to create and institutionalize new organizational models and working patterns. For instance, an alter in institutional routine relates to the duration's shift in the project's lifecycle. The delivery of ultimate service is the normal project end; instead, the objectives of the PM process are starting to take into account the "usage" of investment of the project yonder the end of project activities. This fundamental change links to the concept of sustainability that consequently arises in the need to:

- Contribute to the optimization of the merchandise case of the investment initialized by the project;

- Control the project complexity and project dynamics;

- Constantly adjusts the project frontiers.

In other words, sustainable economic and societal growth built through projects is not solely a technical matter, but it requires institutional change (Scott, 2008: p. 219). Sustainability has mainly been researched in correlation to the area of organizational management and strategy where the concept is related to organizational performance and benefits when integrated into core processes (Gareis et al., 2013).

The Project Management Institute (PMI) emphasizes that management is driven by organizational strategies and that projects are a means to deliver the organizational strategy in an effective manner (PMI, 2013). Therefore, the adjustment between an organization and its projects becomes important to ensure effective results. This requires project management procedures to be influenced by sustainable practices as Silvius et al., (2012), Gareis et al., (2013) and Kivilä et al., (2017) argued that the current factual research implies that sustainability should be integrated into existing project management approaches rather than as separate systems, hence, reducing back-and-forth linking the aspects of sustainability. Similarly, Silvius et al., (2012) studied how to incorporate sustainability within frequently used project methodologies. Given this, the authors tell how sustainability as a concept impacts and changes the project management profession, including how it impacts the most regular standards of project management. Presently the study reviews the literature on various issues on the sustainability facets of project management which has been presented. Based on the literature, a lot of research scopes have been obtained for the buildings, the 
models, tools, methods, and techniques to integrate and scale project management and sustainability. Silvius \& Schipper (2010) said that it is generally perceived that sustainability in project governance concerns integrating economic, environmental, and social aspects in management or projects, and that project sustained should be viewed on the level of the project outcome and its effect. Silvius \& Schipper (2010) coined the precision of sustainable project management out of combining the triple-P elements from sustainability and its life cycle outlook: Sustainable project management can be project-conformed change in policies controlled, assets or organizations, regarding the economic, social, and environmental effects of the project, its outcome, and its impact, for now, and in the future generations.

Furthermore, the appraisal of sustainability must contain certain critical parameters to scale sustainability and can represent a decisive and transparent role for all relevant stakeholders while considering remarkable decisions in the project directive. This was underpinned by Silvius \& Schipper (2010) who have said that sustainability is seen as a broad mission factor in major project management guidelines of PMBoK and ICB3. They give three reasons why they believe that sustainability should be on the agenda of project managers:

- Investments in projects that are considered sustainable are less susceptible to the monetary crisis as non-sustainable projects;

- Companies that are robust in their sustainability likeness, some banks, barely lose value than other banks;

- Integrating criteria on sustainability by public organizations in their procurement policies, braces companies to be more active in this area.

Within this context, the paper is seen to be opportune. The role project managers play is most likely to be particularly necessary as a rising trend towards "projectification" (i.e. the re-organization of tasks and activities as projects, this shows that work is now being carried out in a sequence of (often multi-team) "projects" rather than a linear mass production line system or method of organization, where items or processes are transferred to the next "experts" in the system which places project leaders in an outstanding economic and societal position.

The project leader is tasked for all activities that are needed to provide the project deliverables thus attention on what role project managers play in sustainability when the project leader is responsible for delivering this content, who then is responsible for integrating sustainability in the process? Which project governance role has the highest responsibility to incorporate sustainability aspects in project management? Project managers need to ask themselves how the entirety of sustainability would be within their Projects. Whether the scope is only narrowed to the out-turn of the project or does it concern more and in what manner does it have a connection to the organization within which the project takes place. Remarkably, the project sponsor is solely in charge of the project. He manages the content of the project, finances and ensures focus on 
the business premise. Relatively, project sponsors also have the responsibility for incorporating sustainably in content and business justification. This implies project leaders can incorporate sustainability within his project management process. To what level is he able to do so? Are there sides within the project management process where his influence is the biggest and the smallest? The research question is expounded as follows: What role does a project leader have in integrating sustainability in projects and the project management process?

\subsection{Sustainability in Projects}

However, in defining sustainability in process-based management, research work presented by (Silvius et al., 2012) considers mainly "Sustainability within projects and project management as the development, management and delivery of project-organized alter in policies, resources, processes, assets or organizations, considering the six principles of sustainability, in the project, its outcome, and its effect." These six principles are:

- stabilizing or coordinating social, environmental and economic interests;

- both interim and continuing orientation;

- both local and worldwide orientation;

- values and ethics;

- transparency and accountability; and

- Consuming income, not capital. Ethicality and social standards in projects should be completed.

Project Management Association (2015), Project Management Institute (2010) issued "Codes of Ethics and Professional Conduct" which foreground consideration and incorporation of ethics and values in the projects. Clear blueprint and plan of action for the projects imply how the policies and decisions of a company will have an environmental and social effect (ISO, 2010). The company will be held responsible for its policies and procedures' effects (ISO, 2010). Companies should open up and be proactive in communication with all stakeholders including the consequences on nature, society in short as well as in long-horizon to achieve sustainability into project management (Silvius et al., 2012; Khalfan 2006; Taylor 2010). Project managers are presently allowed by project management procedures to give "only the required information" (Project Management Institute, 2013).

There has been some research which presents works on the integration of sustainability in project Management mentioned some sets of factors from a distinct view (Fernández-Sánchez \& Rodriguez-Lopez, 2010; Labuschagne \& Brent, 2005) and on the premise of the triple bottom line approach. Aforementioned incorporation of financial, natural and public factors in project management does not allow a comprehensive approach to sustainability for project management. A factual observation for Brazilian industries on the premise of triple bottom line variables was performed by Martens \& Carvalho (2017). Authors studied that satisfactorily triple bottom line approach is mainly related to the strat- 
egy and view of the project, which may vary from one project to another. Hence a gap is studied as being sufficient for the development of universally accepted sustainability variables which can be related to the majority of projects to gauge and connect the possible sustainability in them.

\subsection{Selection of Measures in Sustainable Project Management}

Projects are identified to take a crucial part in the sustainable development of organizations and the academic debate on the relationship between project management and sustainability is emerging. The role of the project manager is highlighted in the sustainable management of a project and it can be concluded that the central position of the project manager provides him/her the opportunity to influence many aspects of the project (Silvius \& De Graaf, 2019).

Project lifecycle; Many researchers discussed the induction of sustainability in the area of project management (Gareis et al., 2009, 2013; Labuschagne et al., 2005, Labuschagne \& Brent, 2006; Eid, 2009; Silvius et al., 2012). The induction of sustainability is associated to the project lifecycle and has some restraint towards the projects of short duration. Brent \& Petrick (2007) and Heuberger et al. (2007) explored the effect on the environment in light of Kyoto protocol and the project life cycles. The project lifecycle is mostly coherent with the product or deliverable which is developed from the project (Labuschagne \& Brent, 2006), so while locating the sustainability in project life cycle, the product lifecycle and final deliverable life cycle should also be taken into account (Labuschagne \& Brent, 2006). Taylor (2008) and Silvius \& Schipper (2014) argued succinctly that sustainability needs to be embodied into every stage throughout the project life cycle. Every phase of the life cycle of the project needs sustainability to be incorporated. Sustainable project management needs taking appropriate measures towards achieving it.

The iron-triangle is a widely applied approach appropriate for selecting measures in project management. The iron-triangle represents triple constraints namely time, quality, and cost. The stage-gate approach also gauges project success on time, quality, uncertainty, and cost parameters (Project Management Institute, 2013). The sustainability criteria must be taken into consideration while selecting the project management measures.

Regional, National, and International Projects: The project location is pivotal in determining its sustainability. Recently, international economies are very diplomatic towards the losses and gains, so it has become highly imperative to determine and appraise the sustainability effects at regional, national and international level. To meet out the competition it is studied that companies are guided by the various global policies, global partners, global stakeholders, global vendors and global customers etc. Projects, can be related to the universal supply of products, materials or universal use of resources into the projects located at different sites nationally or internationally Considering of projects point of view, it always becomes necessary to take note of the level of the project i.e. sustaina- 
bility whether the project is regional, national or global. Sustainable project management can be attained by taking right procedures towards it. A thorough literature review reveal a common measure used in project management called the iron triangle approach. A widely used approach for the right choice of procedures in project management is iron triangle (Papke-Shields et al., 2010; Atkinson, 1999).

The iron-triangle is known as triple constraint namely time, quality and cost. The stage gate approach also considers a project success on time, quality, uncertainty, and cost parameters (Project Management Institute, 2013). The sustainability standard should be put into consideration while choosing the procedures in the project management. Authors studied decision making as the most analytic and significant action to reject and counter various likely threats and challenges of green construction projects. In order to take right decisions and choosing of right measures, the decision makers should enhance and build their information and skills in core areas and subjects to make successful and sustainable projects. It is seen that the methods of choosing right measures or consideration for appropriate decision are very important for sustainable Project management. Furthermore, it is also known that the right decision making is a distinct feature for any decision maker which should be constantly enhanced to attain high productivity and success rate in the actions taken for sustainable project management in light of the taken decisions. A key factor in partnership development is acknowledging the role of collaborative relationship. To increase the collaboration benefit, existing studies sought various antecedents such as collaborative awareness, collaborative culture and technology-driven inter-organizational systems and supplier-buyer cooperation (Shin et al., 2019).

Based on the literature review, a potential study gap for development, analysis, and use of evolutionary computing algorithms for taking efficient decisions on sustainable project management is also observed

\subsection{Sustainable Project Business Policies}

Attaining sustainability in project management is seen as a significant task which also ensures value and benefits in overall operations. Sustainability is easily gauged by three common factors which are: environmental factor, financial factor and social factor. Infrastructural projects, product sustainability and development process are imperative in the light of having high impacts on environmental and social factors. Sustainable project management becomes necessary for infrastructure projects experiencing differentiations to the society and engaging collaborators with varied interests and expectations.

Having power over the project promotes achievement of set targets of the project but for attaining sustainability in projects more versatile sustainability inclined project control practices should be considered, especially in control of infrastructure projects (Kivilä et al., 2017). The control exerted on project execution phase for an infrastructure project is highly desirable for sustainability in 
project management. There must be an appropriate consideration for usage of sustainability during the project execution, project control procedures and mutual agreement between the project stakeholders.

Nowadays research aims at sustainability by targeting the project and also adopting into the project management procedures (Gareis et al., 2013; Silvius \& Schipper, 2014). Researchers have analyzed and assessed sustainability-driven performance factors for the project management but little attention has been given to the building the project control procedures and practices to achieve throughout sustainability in the project targets particularly in the field of infrastructure delivery projects. Based on literature, it is seen that there is a limited widely accepted interpretation for the sustainable project management or the sustainability in project management (Aarseth et al., 2017).

Broadly speaking, the concept of sustainability can be categorized into three core categories which are connected with each other and are equally significant from sustainable project operations and management point of view. The three categories are environmental sustainability, financial sustainability, and social sustainability. Earlier the main aim of project operations was to maintain high growth rate and high financial sustainability with least considerations on the environmental sustainability and social sustainability, but now it is globally accepted that environmental sustainability, social sustainability and financial sustainability are equally significant for achieving the purpose of sustainable project management (Elkington, 1994) also seen as the triple-bottom-line approaches. Today the business leader's schemes are more inclined towards yielding broader business profits, ethics and the flexible values instead of only executing their immediate project goals (Atkinson, 1999). The organizations should include sustainability into their project management practices and now should avoid considering only quality, cost and time factors (Silvius \& Schipper, 2014). The projects, especially infrastructure projects having a certain impact on natural resources and society, must include and evaluate the sustainability of the project and the sustainability of the delivery process holistically before execution of any infrastructure Projects.

The project leader is tasked for all activities that are needed to provide the project deliverables. Within projects, the project sponsor takes ultimately responsibility for the project. He offers finances, gives direction on the content of the project and enables that the attention is kept focused on the business justification (Hermarij, 2010). Further, the assessment of the sustainability should include critical framework to gauge the sustainability and can act as a decisive and straightforward role for all the stakeholders while making significant choices in the management of the projects (Mathur et al., 2008; El-Haram et al., 2007; Thomson et al., 2011). El Haram et al. (2007) and Thomson et al. (2011) identified conceptual and technical issues for the sustainable project management are yet to be described. Critical parameters to scale sustainability in the projects are the weighting parameters in the multi-objective sustainable project management 
for completing its life cycle is gauged at the initial stage properly on seven critical parameters namely: Safety, Transparency, Ethicality, Nature-friendly, Social acceptability and Fulfilling stakeholders and expectations of the customer.

Turner (2010) takes a different perspective regarding sustainability in growth and Project management. He deals with all project governance roles and points towards commerce as an anonymous group. He has mentioned the duty for main players within projects and programs for the execution of sustainable initiatives. He makes an argument that in project management, sustainability can be gained both in the product of the project and in the process of delivering the product. He focused on six concepts of project management that are relevant for incorporating, aspects of, sustainability: 1) project objectives; 2) project scope and schedule; 3) project resources, cost, income, and risk; 4) project organization; 5) project context; 6) project management process design. He also mentions that for the implementation of sustainability no research has been done yet on responsibility for different participants on projects and programs.

Sustainability principles of Turner include; 1) holistic approach; 2) long term view; 3) large scale; 4) reducing risk and uncertainty; 5) values and ethics; 6) participation. (Gareis et al. 2009), coupled with a model for governance for projects and programs, suggests what the responsibility for some of the main players may be.

However, this research used six of Turner's sustainability principles during the data gathering but only four were applicable regarding the case and they include; 1) Holistic approach; 2) Long term view; 3) Risk reduction; and 4) Participation. Table 1 represents what responsibilities some of the role performers may have for six of the principles of sustainability. Turner (2010) has changed the position of Values and Ethics because he believes that this is where it begins. What are the corporate standards of each client organization and the delivery organization, what is their attitude towards corporate social responsibility, and what is their ethical position on preserving the environment for our next generation?

Table 1. Sustainable development and project governance roles (Turner, 2010).

\begin{tabular}{ccccccc}
\hline \multirow{2}{*}{$\begin{array}{c}\text { Sustainability } \\
\text { principles }\end{array}$} & Client/owner & $\begin{array}{c}\text { Program } \\
\text { Manager }\end{array}$ & $\begin{array}{c}\text { Program } \\
\text { Sponsor }\end{array}$ & $\begin{array}{c}\text { Project } \\
\text { Manager }\end{array}$ & $\begin{array}{c}\text { Senior } \\
\text { User }\end{array}$ & $\begin{array}{c}\text { Senior } \\
\text { Supplier }\end{array}$ \\
\hline Values and Ethics & $\mathrm{Hi}$ & Med & Med & Med & Med & Med \\
Holistic Approach & $\mathrm{Hi}$ & Med & Med & Lo & Lo & Lo \\
Long term view & $\mathrm{Hi}$ & $\mathrm{Hi}$ & Med & Lo & Lo & Lo \\
Large scale & $\mathrm{Hi}$ & $\mathrm{Hi}$ & Med & Med & Lo & Lo \\
Risk reduction & $\mathrm{Lo}$ & $\mathrm{Hi}$ & $\mathrm{Med}$ & $\mathrm{Hi}$ & $\mathrm{Hi}$ & $\mathrm{Hi}$ \\
Participation & Lo & Med & Med & $\mathrm{Hi}$ & $\mathrm{Hi}$ & $\mathrm{Hi}$ \\
\hline
\end{tabular}

Note: this table is derived from Turner's model, 2010. 


\section{Methodology}

This research paper studied literature and on the premise of a case study. Usually, in order to achieve the goal of the paper, the case study questions are supposed to be of "why" or "how" questions. In this research, a case study is conducted on account of the paper as being reasonably suitable to show whether or not a project leader does have an influence on the execution of Sustainability within the project management process just as similar research has been done at the University of Applied Sciences, Utrecht. This paper makes an attempt to create discussion of which project management roles have what influences on aspects of sustainability within the project management process. First and foremost, a literature study was conducted. Nearly all literature was found via the "Science Direct" database. The suggested words that were used to search for the literature were: "sustainability, project management", "corporate social responsibility". Other papers have been found by going to the reference list of the papers that were chosen. Several research papers were found in an obscure way.

\section{Data Collection}

After studying literature, the research question was redefined and a case study was prepared and conducted upon which data was drawn from this case, processed, analyzed, and compared to the theory. Finally a conclusion was drawn from the data. Turner's model is riveting due to being the premier model that tries to generate a discussion on the responsibilities that different project governance roles can have regarding the implementation of sustainability principles. He has made suggestions about what may be the responsibilities of these key players. This paper begins to try to test Turner's suggestions. For this, a case study technique has been drawn. The selected case is a project called "Anli Homeland" project development and construction with the land near the Anhui University of Science and Technology new campus for the development. At present, the company is making preliminary preparations for the project due to their experience of working with sustainability and aims to be at the forefront in the real estate industry where they see increased demand and need for sustainability. The project case was studied and four interviews are conducted.

The interviews are conducted from the program leader who is the chairman of the real estate, the main project manager who represents the general manager, two deputy project leaders, and the client. According to Bryman \& Bell (2015) qualitative research is preferable in studies of explorative character as it enables non-numeric data collection, including subjective data such as thoughts, emotions, and personal experiences. This approach was required as a way of fully understanding the dynamics related to the issues initially described by Anhui Li Gong Real Estate Co., Ltd. Hyett et al., (2014) asserted that researchers use the case study in view of identifying what is common about that case and what is specific about it, and Thomas (2011) and Yin (2012) both expounds that the case study can assist us to explain how or why something happened. When the inves- 
tigator has restricted power over events, and when the attention is on a present day event within some significant features of real-life events. This paper is based on case study research because two of the three preconditions are met. The case study rightly suits this study on the big theme of sustainability because the method grants the investigator to abide by holistic and its significant features are particularly meaningful in trying to grasp the true meaning, preconditions and influence of sustainability in projects and project management.

Only a few defining factors for the case study as a whole seems to be persistent in previous literature. One could say that these factors are the mandatory features of a case study research. Consequently, when doing a case study, the researcher is offered flexibility and a big opportunity to select the type of case study which suits the researcher's specific needs to do analytic generalization. The flexibility includes the possibility to choose in terms of size and time span for cases, the number of cases encompassed in the study, ways of collecting data and building theory from the study with which the empirical outcome of the case study are compared since the latter is found vulnerable in proving or rejecting theories (Yin, 2003). Turner's (2010) model, which is partly based on the findings of Gareis et al. (2009), is the theory that will be tested in a single case. Turner has demonstrated the responsibilities that the role performers may have for the six principles of Sustainability. It is clear that collaboration among different roles and hierarchical levels, long maintenance responsibilities and early involvement of contactors all carry great potential. Decision makers also seem to have high aims and expectations generally regarding such collaboration and integration (Erickson et al., 2019). In this case study four of the sustainability principles and four of the project governance roles are considered (Table 2). This shows the basic assumption of the case study. It is investigated whether the assumptions made by Turner are also true for the project "Anli Homeland" project of the Anhui Li Gong Real Estate Co., Ltd.

The real estate company was established in July 2012 with an inscribed capital of 10 million Yuan. It is fully invested by China Chemical Engineering Huainan Zhenhua Construction and Installation Company. The company's qualification level is tentative; the main development task soon is to develop and build a residential property with full property rights through the market of exploits of the

Table 2. Case study basic assumption (derived from Turner, 2010).

\begin{tabular}{ccccc}
\hline \multirow{2}{*}{$\begin{array}{c}\text { Sustainability } \\
\text { principles }\end{array}$} & Client/Owner & $\begin{array}{c}\text { Program } \\
\text { Manager }\end{array}$ & $\begin{array}{c}\text { Project } \\
\text { Manager }\end{array}$ & $\begin{array}{c}\text { Senior } \\
\text { Supplier }\end{array}$ \\
\cline { 2 - 5 } & $\mathrm{Hi}$ & $\mathrm{Hi}$ & $\mathrm{Med}$ & $\mathrm{Hi}$ \\
Holistic Approach & $\mathrm{Hi}$ & Lo & Lo & $\mathrm{Hi}$ \\
Risk Reduction & $\mathrm{Lo}$ & $\mathrm{Lo}$ & $\mathrm{Lo}$ & $\mathrm{Lo}$ \\
Participation & $\mathrm{Hi}$ & $\mathrm{Hi}$ & $\mathrm{Hi}$ & $\mathrm{Hi}$ \\
\hline
\end{tabular}


new campus. On October 15, 2015, through a public auction, Anhui Ligong Real Estate purchased 358 acres of development and construction land near the new campus for building, construction, and growth of the "Anli Homeland" project.

Presently, Anhui Ligong Real estate is making preparations preliminarily for the project in respect to their experience of working with sustainability and aims to be at the forefront in the real estate companies where they see increased demand and need for sustainability. The company is with the firm belief that incorporating sustainability in projects would lead to a greater value-adding effect for its clients and an enhanced competitive advantage for both. Therefore, methods to achieve this are sought after and desired.

However, acting as external consultants in major projects, their project managers will be overblown by the client's targets and demands. The customer is the main executive in decision making, thus affecting the project leaders' influential level. This requires supportive functions and methodology which can help managers of a project to raise sustainability questions, issues, and solutions to customers. As such methods and routines are lacking, today's sustainability work remains highly person and context-dependent. An ignorance and insecurity about the sustainability concept seem to exist amongst project managers, resulting in limited sustainability integration in projects. Some project managers feel uncomfortable about raising questions regarding sustainability aspects, issues, and solutions towards customers, thus, causing negligence of continuity in projects.

The ambition with integrating sustainability through new methods and routines is to mitigate this negligence together with raising the confidence amongst project leaders to actively be involved in sustainability work. This study has been initiated in collaboration with Anhui Ligong Real Estate Company, as the company strives for becoming more sustainable in projects. Anhui Ligong Real Estate Co., Ltd is the place where you put to rest all your real estate issues because there exist sustainability network and a sustainability coordinator together with his normal role as a project manager, has a responsibility for communicating sustainability in its region, developing employees into sustainable project leaders and emphasizing sustainability work. All the project goals are in relation to sustainability. Are these objectives and with that, the deliverables signify sustainability, or is it also prominent that these deliverables are built-in sustainably? Whose role is this? And then, what is the project leader's capacity on some developing processes of the deliverables? In this project, writing of the project plan does not involve the project manager, which could mean that he has limited or no influence on the way sustainability is integrated within the project or implemented in the project management process? Turner (2010) explains that the owner is fully accountable for the holistic approach. The responsibility the program leader has is to instruct and guide the project leader in terms of a holistic approach. In the long-term view, he stated that again the client should set the policy for the long-term view, but it is the part of the program leader to ensure it 
is implemented. The strategy for collection of data that is used is that first the questionnaire was set up after which the project was selected for discussion with the program leader. The case was studied and finally, five interviews were conducted. However, first, the questionnaire was tested in an interview with the Chairman of the company.

\section{Case Study Results and Discussion}

The outcome of the case study relates to five interviews that were conducted. The interviews are conducted with the program manager; the project manager, two deputy project leaders, and the client of these five interviews all are valid for this interview because they are major partners. This research is rooted on Chinese Construction Company as its case study.

Language is a barrier in communicating which is not a factor to be left out. It has been time-consuming because interpretation has to be done. Sometimes the actual meaning is lost but as a researcher, one has to get the cards right by re-structuring all these to make an imperative meaning relating to the study.

Again, the staff of this company can be found within the university administration building in different offices, thus the study is not able to consider focused group discussion but rather one to one questionnaire administration due to different times of staff availability. It is assumed by the interviewees that both long-term view and holistic approach are important aspects of sustainability that are present within the project. However, the baseline has been set and the effect of sustainability assessment has been conducted. This enables easy measurement of the effects of the project within "Anli Homeland". In these decisions, consideration of issues, risks, and the needs of future generations are addressed. This is natural as it is found to come in when dealing with sustainability aspects.

This perception also goes for social learning aspects, innovation, and design. Additionally, decision making towards sustainability is very imperative by company consultants who exhibit superior leadership. These decisions include;

- Adopting green environmental protection "ground source camshaft system" by heating and cooling. Green building includes several components that manifest what (Shi et al., 2016) mentioned as Energy Efficiency and Renewable Energy, Water Efficiency, Environmentally Recommended Building Materials, and Specifications, Waste Minimization, Toxics Minimization, Indoor Air Quality, and Smart Growth and Sustainable Development.

- Innovation through optimizing design. Green building design includes finding the parity on both homebuilding and a sustainable environment.

- Conduct market research; many students are accepted for practical learning to enable them to gain skills and broaden their mindset as well as boost the research market.

All interviewees filled out Turner's table. In Table 3, the deviations seen between Turner's assumptions and the outcomes of this case study are made clear. In this paper, it is interpreted that the program manager's responsibility is high 
Table 3. Start of case study (derived from Turner, 2010 and results).

\begin{tabular}{cccccccccc}
\hline \multicolumn{1}{c}{ Project governance roles } \\
\hline $\begin{array}{c}\text { Sustainability } \\
\text { Principles }\end{array}$ & \multicolumn{1}{c}{ Client/Owner } & Program Manager & Project Manager & Senior Supplier \\
\cline { 2 - 10 } & Turner & Case & Turner & Case & Turner & Case & Turner & Case \\
\hline Holistic Approach & $\mathrm{Hi}$ & $\mathrm{Hi}$ & $\mathrm{Med}$ & $\mathrm{Hi}$ & Lo & Med & Lo & $\mathrm{Hi}$ \\
Long term view & $\mathrm{Hi}$ & $\mathrm{Hi}$ & $\mathrm{Hi}$ & Lo & Lo & Lo & Lo & $\mathrm{Hi}$ \\
Risk Reduction & Lo & Lo & Hi & Lo & $\mathrm{Hi}$ & Lo & $\mathrm{Hi}$ & Lo \\
Participation & Lo & Lo & Med & Hi & Hi & Hi & Hi & Hi \\
\hline
\end{tabular}

in respect of the holistic approach and participation but has low responsibility regarding the long-term view as well as the risk reduction principle. This is because the program leader is expected to have the bigger picture and expected benefits of the entire program. Comparatively the program leader is perceived to have more responsibility in a holistic approach. On the other hand, the project leader has a medium responsibility with reference to the holistic approach; he also has a high responsibility regarding participation and low responsibility for both long term view and risk reduction. Ideally, project managers concentrate on individualistic projects by focusing on achieving results.

The senior Supplier and client/owner have a towering responsibility for these three principles which are holistic approach, long-term view, and participation but have a low responsibility for risk reduction. The client/owner has the highest responsibility for implementing project sustainability. The client/owner draws the limit for the entirety of the program by determining the right steps to take as to whether to continue the program or not by delivering the expected program outcome. The program and project leaders must receive the right information from above.

The deputy project managers only focus on their project, on delivering the expected project results. The responsibility seems to be defined orderly. The program leader has more responsibility than the project manager. Usually, the program leader must forecast. One of the deputy project managers reiterated: "we help raise funds as a way of Cooperative building. We work hand in hand with Program managers to ensure a quiet and green environmental protection, suitable for travel and ensure it is a livable ecological community for everyone". Third-party agencies conduct environmental assessments to know if the said project is sustainable enough to meet the needs of the future generation. "The holistic approach of the program leader must be high as well as participation once, the project is not on its own and demands high participation amongst most of principles from the scratch to finish. The general manager said he perceives holistic approach responsibility as decision making towards sustainability by company consultants who exhibit superior leadership. These decisions include; Innovation through optimizing the design because he's constantly rotating the different scale-levels. 


\section{Conclusion}

It is rooted on the perception that interviewees internally stimulate in addition to being responsible for sustainability to themselves and the other project governance roles. Also, it is recognized that they believe that an individual is being asked to fulfill a role in a sustainability project because of one's empathy with the context that can be both sustainability and one's profession. Program leaders only work with motivated project leaders if they are asked to work based on their like-mindedness and skills with the content and context of the project. The project leaders are merely content project managers who do not necessarily have to execute project management tasks that are not about their profession, like communicating with several stakeholders, budgeting, and quality management. The main research question of this case study draws its answer as that it is believed that a project leader can influence the way sustainability is implemented in the project and the project management process. His influence is regarded as "medium" for a holistic approach high for participation.

However, this perception is formed on the notion that project leaders are internally stimulated to work on a viable project and achieve a sustainable outcome. It is an interesting result that should be further explored in different researches because it also gives rise to new debates. Based on this, does it mean that the extent to which sustainability is implemented in a project that is dependent on the project leader's predilection while the project leader is seen to be only chosen to acquire a preset project result or this assumption is not a given solution but just a reflection of the selected case to generate further discussion?

\section{Suggestions and Recommendations}

The research on incorporating sustainability within project management could be beneficial from further research.

1) A suggestion is to conduct similar investigations as this study seeks to generate an expanded theoretical knowledge of how sustainability is feasible in projects. Another interesting research topic is to investigate how feasible sustainability can be implemented with a practical approach to a project-based case study. This would constrict the topic and allow deep-probing research that could generate concrete visualization of integrating sustainability within projects by testing theory in practice.

2) This research contributes with widespread recommendations of how methods concerning sustainability work can be outlined and utilized within Anhui Ligong Real Estate Co., Ltd. Anhui. It is believed that some employees exhibit greater insight into an organization that is more eligible to decide in detail how these methods should be designed, realized, and utilized to fit in a managerial context. Therefore, Anhui Ligong Real Estate Company Limited clarifies who will be seen as having the responsibility for the methods and their implementation.

3) The Sustainable Development Goals (SDGs) as a pivot. The main sugges- 
tion for Anhui Ligong Real Estate Company to use the SDGs as the main role when working with sustainability as a uniform outline which creates a clear way of working consequently to mitigate some challenges, limitations and increase the benefits and values associated with integrating sustainability within projects in addition to creating new methods as the SDGs are globally recognized, utilized by customers, and considered as a meaningful tool by project managers.

4) E-learning; Web-based training is a great tool for reaching out to all project managers at Anhui Ligong Real Estate Co., Ltd. It will ensure that everyone acquires the knowledge and awareness of the topic of sustainability. E-learning should be mandatory to increase the orientation connecting top management and project managers. This will help take the edge off the challenges related to responsibilities, lack of directives, and the differentiating perceptions of sustainability.

5) Organize summits and workshops that focus on sustainability; Motivating and engaging project leaders in sustainability work are important. Summits and workshops are currently used in the company regions and regarded as a significant way to inspire employees and must be a medium to communicate the principles and values that are derived from sustainability, with regards to the company but also personal values stemming from the role as a project manager. It will also emphasize the commitment from top management towards sustainability within the urban development industry. Internal workshops should serve two purposes;

- Highlight the sustainability coordinators' role and their ability to assist project managers in working towards sustainability.

- It should serve as a realistic opportunity for project leaders to concretize sustainability aspects in real-life projects as a way of challenging them to expand their view of sustainability and showing that sustainability can be addressed and approached differently depending on the project context.

\section{Conflicts of Interest}

The authors declare no conflict of interest.

\section{References}

Aarseth, W., Ahola, T., Aaltonen, K., Økland, A., \& Andersen, B. (2017). Project Sustainability Strategies: A Systematic Literature Review. International Journal of Project Management, 35, 1071-1083. https://doi.org/10.1016/j.ijproman.2016.11.006

Atkinson, R. (1999). Project Management: Cost, Time and Quality, Two Best Guesses and a Phenomenon, Its Time to Accept Other Success Criteria. International Journal of Project Management, 17, 337-342. https://doi.org/10.1016/S0263-7863(98)00069-6

Brent, A. C., \& Petrick, W. (2007). Environmental Impact Assessment during Project Execution Phases: Towards a Stage-Gate Project Management Model for the Raw Materials Processing Industry of the Energy Sector. Impact Assessment and Project Appraisal, 25, 111-122. https://doi.org/10.3152/146155107X205832

Bryman, A., \& Bell, E. (2015). Business Research Methods (4th ed.). Oxford: Oxford Un- 
iv. Press.

Eid, M. (2009). Sustainable Development \& Project Management (p. 176). Cologne: Lambert Academic Publishing.

El-Haram, M., Walton, J., Horner, M., Hardcastle, C., Price, A., Bebbington, J., \& Atkin-Wright, T. (2007). Development of an Integrated Sustainability Assessment Toolkit. In Conference Proceedings, International Conference on Whole life Urban Sustainability and Its Assessment (pp. 30-44). Glasgow, UK.

Elkington, J. (1994). Towards the Sustainable Corporation: Win-Win-Win Business Strategies for Sustainable Development. California Management Review, 36, 90-100. https://doi.org/10.2307/41165746

Elkington, J. (1999). Cannibals with Forks: The Triple Bottom Line of the 21st Century Business. West Sussex: Wiley \&Sons Ltd.

Erickson, P. E., Volker, L., Kadefors, A., Lingegård, S., Larsson, J., \& Rosander, L. (2019). Collaborative Procurement Strategies for Infrastructure Projects: A Multiple-Case Study. Proceedings of the Institution of Civil Engineers Management, Procurement and Law, 172, 197-205. https://doi.org/10.1680/jmapl.19.00016

Fernández-Sánchez, G., \& Rodríguez-López, F. (2010). A Methodology to Identify Sustainability Indicators in Construction Project Management-Application to Infrastructure Projects in Spain. Ecological Indicators, 10, 1193-1201. https://doi.org/10.1016/j.ecolind.2010.04.009

Gareis, R., Huemann, M., \& Martinuzzi, A. (2009). Relating Sustainable Development and Project Management. IRNOP IX, Berlin 52.

Gareis, R., Huemann, M., Martinuzzi, A., Weninger, C., \& Sedlacko, M. (2013). Project Management and Sustainable Development Principles. Newtown Square, PA: Project Management Institute.

Hermarij, J. (2010). The Better Practices of Project Management. Ouderkerk aan de Amstel: Dhirita B.V.

Heuberger, R., Brent, A., Santos, L., Sutter, C., \& Imboden, D. (2007). CDM Projects under the Kyoto Protocol: A Methodology for Sustainability Assessment-Experiences from South Africa and Uruguay. Environment, Development and Sustainability, 9, 33-48.

Hyett, N., Kenny, A., \& Dickson-Swift, V. (2014). Methodology or Method? A Critical Review of Qualitative Case Study Reports. International Journal of Qualitative Studies on Health and Well-Being, 9, 23606. https://doi.org/10.3402/qhw.v9.23606

ISO (2010). ISO 26000, Guidance on Social Responsibility. Delft: Nederland Normalisatie Instituut.

Khalfan, M. M. (2006). Managing Sustainability within Construction Projects. Journal of Environmental Assessment Policy and Management, 8, 41-60. https://doi.org/10.1142/S1464333206002359

Kivilä, J., Martinsuo, M., \& Vourinen, L. (2017). Sustainable Project Management through Project Control in Infrastructure Projects. International Journal of Project Management, 35, 1167-1183. https://doi.org/10.1016/j.ijproman.2017.02.009

Kleindorfer, P. R., Singhal, K., \& Wassenhove, L. N. (2005). Sustainable Operations Management. Production and Operations Management, 14, 482-492. https://doi.org/10.1111/j.1937-5956.2005.tb00235.x

Labuschagne, C., \& Brent, A. C. (2005). Sustainable Project Life Cycle Management: The Need to Integrate Life Cycles in the Manufacturing Sector. International Journal of 
Project Management, 23, 159-168. https://doi.org/10.1016/j.ijproman.2004.06.003

Labuschagne, C., Brent, A. C., \& Van Erck, R. P. (2005). Assessing the Sustainability Performances of Industries. Journal of Cleaner Production, 13, 373-385.

https://doi.org/10.1016/j.jclepro.2003.10.007

Martens, M. L., \& Carvalho, M. M. (2017). Key Factors of Sustainability in Project Management Context: A Survey Exploring the Project Managers' Perspective. International Journal of Project Management, 35, 1084-1102. https://doi.org/10.1016/j.ijproman.2016.04.004

Mathur, V. N., Price, A. D., \& Austin, S. (2008). Conceptualizing Stakeholder Engagement in the Context of Sustainability and Its Assessment. Construction Management and Economics, 26, 601-609. https://doi.org/10.1080/01446190802061233

Papke-Shields, K. E., Beise, C., \& Quan, J. (2010). Do Project Managers Practice What They Preach, and Does It Matter to Project Success? International Journal of Project Management, 28, 650-662. https://doi.org/10.1016/j.ijproman.2009.11.002

PMI Project Management Institute (2010). The Bottom Line on Sustainability (p. 8). Newtown Square, PA: Project Management Institute, Inc.

PMI Project Management Institute (2013). A Guide to the Project Management Body of Knowledge (PMBOK Guide). Newtown Square, PA: Project Management Institute, Inc. https://doi.org/10.1002/pmj.21345

Scott, W. R. (2008). Lords of the Dance: Professionals as Institutional Agents. Organization Studies, 29, 219-238. https://doi.org/10.1177/0170840607088151

Shi, X., Tian, Z., Chen, W., Si, B., \& Jin, X. (2016). A Review on Building Energy Efficient Design Optimization Rom the Perspective of Architects. Renewable and Sustainable Energy Reviews, 65, 872-884. https://doi.org/10.1016/j.rser.2016.07.050

Shin, N., Park, S. H., \& Park, S. (2019). Partnership-Based Supply Chain Collaboration: Impact on Commitment, Innovation, and Firm Performance. Sustainability, 11, 449. https://doi.org/10.3390/su11020449

Silvius, A. J. G., \& De Graaf, M. (2019). Exploring the Project Manager's Intention to Address Sustainability in the Project Board. Journal of Cleaner Production, 208, 1226-1240. https://doi.org/10.1016/j.jclepro.2018.10.115

Silvius, A. J. G., \& Schipper, R. (2010). A Maturity Model for Integrating Sustainability in Projects and Project Management. In 24th IPMA World Congress.

Silvius, A. J. G., Schipper, R., Planko, J., van den Brink, J., \& Köhler, A. (2012). Sustainability in Project Management. Farnham: Gower Publishing.

Silvius, A. J., \& Schipper, R. P. (2014). Sustainability in Project Management: A Literature Review and Impact Analysis. Social Business, 4, 63-96. https://doi.org/10.1362/204440814X13948909253866

Taylor, T. (2008). A Sustainability Checklist for Managers of Projects. http://www.pmforum.org/library/papers/2008/PDFs/Taylor-1-08.pdf

Thomson, C. S., El-Haram, M. A., \& Emmanuel, R. (2011). Mapping Sustainability Assessment with the Project Life Cycle. In Proceedings of the Institution of Civil Engineers-Engineering Sustainability (Vol. 164, No. 2, pp. 143-157). Thomas Telford Ltd. https://doi.org/10.1680/ensu.2011.164.2.143

Turner, R. (2010). Responsibilities for Sustainable Development in Project and Program Management. In H. Knoepfel, Ed., Survival and Sustainability as Challenges for Projects (pp. 161-174). Zurich: International Project Management Association.

UNCTAD (2014). Best Practice Guidance for Policymakers and Stock Exchanges on Sus- 
tainability Reporting Initiatives. Geneva.

http://unctad.org/en/PublicationsLibrary/diaeed2013d6 en.pdf

Yin, R. K. (2003). Case Study Research Design and Methods. Thousand Oaks, CA: Sage Publications.

Yin, R. K. (2012). Applications of Case Study Research. Thousand Oaks, CA: Sage Publications. 